Article

\title{
Theoretical Calculations on the Mechanism of Enantioselective Copper(I)-Catalyzed Addition of Enynes to Ketones
}

\author{
Hanwei Li, Mingliang Luo, Guohong Tao and Song Qin * (D) \\ Key Laboratory of Green Chemistry and Technology, Ministry of Education, College of Chemistry, \\ Sichuan University, Chengdu 610064, Sichuan, China; lihanwei68@163.com (H.L.); luomlcn@gmail.com (M.L.); \\ taogh@scu.edu.cn (G.T.) \\ * Correspondence: qinsong@scu.edu.cn; Tel.: +86-199-8127-7206
}

Received: 3 July 2018; Accepted: 24 August 2018; Published: 28 August 2018

\begin{abstract}
Computational investigations on the bisphospholanoethane (BPE)-ligated Cu-catalyzed enantioselective addition of enynes to ketones were performed with the density functional theory (DFT) method. Two BPE-mesitylcopper (CuMes) catalysts, BPE-CuMes and ( $S, S)$-Ph-BPE-CuMes, were employed to probe the reaction mechanism with the emphasis on stereoselectivity. The calculations on the BPE-CuMes system indicate that the active metallized enyne intermediate acts as the catalyst for the catalytic cycle. The catalytic cycle involves two steps: (1) ketone addition to the alkene moiety of the metallized enyne; and (2) metallization of the enyne followed by the release of product with the recovery of the active metallized enyne intermediate. The first step accounts for the distribution of the products, and therefore is the stereo-controlling step in chiral systems. In the chiral $(S, S)$-Ph-BPE-CuMes system, the steric hindrance is vital for the distribution of products and responsible for the stereoselectivity of this reaction. The steric hindrance between the phenyl ring of the two substrates and groups at the chiral centers in the ligand skeleton is identified as the original of the stereoselectivity for the titled reaction.
\end{abstract}

Keywords: copper-catalyzed; enantioselective; DFT

\section{Introduction}

Catalytic asymmetric nucleophilic addition of hydrocarbons to ketones is of great interest in organic synthesis, because this reaction is an effective method to obtain quaternary carbon centres [1-8]. Efavirenz and Tripanavir, two enzyme inhibitors with one or more tetrasubstituted centres in their structures, are often used in the treatment of acquired immune deficiency syndrome (AIDS), and therefore such reactions are significant in many pharmaceutical drugs' synthesis [1].

The pioneering work reported by Dosa and Fu in 1998 demonstrated that an excess of methanol allowed for the addition of diphenyl zinc to aromatic and aliphatic ketones with fair to excellent enantioselectivities (up to 91\% ee) [9]. Some reactions of "naked" CO (carbon monoxide) and unsaturated hydrocarbons in the presence of cobalt carbonyls leading to organic and organometallic products were investigated. The carbonylation was found to be regio-selective and the nature of the products highly dependent on the acetylene [10-14]. In 2006, the asymmetric rhodium-catalyzed dienylation of $\alpha$-ketoesters was reported by the Krische group [15]. Then, the conjugated enynes were used as pronucleophiles for the introduction of the dienyl group in the presence of a Walphos rhodium (I) catalyst for the hydrogen mediate coupling on ketones [1]. Later, this catalytic method was applied to enantioselective reductive coupling of 1,3-enynes to heterocyclic aromatic aldehydes and ketones via a rhodium-catalyzed asymmetric reaction [16]. The use of substoichiometric amounts 
of chiral ligands for the asymmetric enantioselective alkynylation of ketones catalyzed by Zn (salen) complexes was pioneered in 2003 by Cozzi. Good reactivity was reached with a $20 \mathrm{~mol} \%$ amount of the salen ligand with enantioselectivities up to 81\% [17-21]. In 2004, Bolm and co-workers reported $C_{1}$-symmetric sulfoximines as ligands in copper-catalyzed asymmetric Mukaiyama-type aldol reactions [22]. Aldol products have been obtained with up to a $99 \%$ ee yield. Then, they developed a new ligand class consisting of $C_{1}$-symmetric aryl-bridged aminosulfoximines in this reaction. Under the optimized reaction conditions, a $10 \mathrm{~mol} \%$ mixture of $\mathrm{Cu}(\mathrm{OTf})_{2}$ and aminosulfoximine in tetrahydrofuran (THF) have outstanding enantioselectivities (up to $99 \%$ ee) with yields up to $90 \%$ [23]. Shibasaki et al. developed a new methodology for the catalytic aldol reaction to ketones. This research group designed new chiral $C_{2}$-symmetric bidentate phosphine ligands. The success of this reaction depended on a unique dynamic ligand exchange between silicon and copper atoms, and this method was applied to a catalytic enantioselective reaction [24].

Among the series of organometallic catalysis reactions, copper catalysis has offered an inexpensive, environmentally friendly alternative to the use of precious metals [25-34]. Shibasaki et al. described a possible solution to a catalytic enantioselective allylation of ketoimines. They developed the general basic methodology for allylation of ketoimines; this method used a CuIF catalyst combined with an $\mathrm{La}(\mathrm{OiPr})_{3}$ cocatalyst and allylboronate as nucleophile [35]. Thus, the copper-based chiral catalysts for the asymmetric allylation of ketones have attracted much attention. Kanai and Shibasaki successfully developed the Cu-DIFLUORPHOS complex-catalyzed enantioselective alkylative aldol reactions and this reaction can be applied to a wide range of substrates. An allenic esters coupling with ketones and dialkyl zincs that deliver $\delta$-lactones with excellent enantioselectivity (typically $>95: 5 \mathrm{er}$.) was described in $[36,37]$. Hoveyda and co-workers described a Cu-catalyzed chemoselective and enantioselective addition to aldehydes and ketones with aryl- or alkyl-substituted allenes and $\mathrm{B}_{2}(\mathrm{pin})_{2}$ (typically > 95:5 er.) [38]. Shimizu Kanai and co-workers developed an efficient catalytic method to generate reactive allylcopper species (typically $>95: 5$ er). Additionally, the allylcopper can be used for subsequent asymmetric carbonyl allylation, providing $1 \mathrm{H}$-isochromene derivatives in excellent enantioselectivity [39]. Hoveyda and co-workers demonstrated that proto-boryl additions to 1,1-disubstituted allenes in the presence of chiral NHC-Cu complexes, $\mathrm{B}_{2}(\mathrm{pin})_{2}$, and $t$ - $\mathrm{BuOH}$ proceed to afford vinyl boronates up to $98 \%$ in yield, and in excellent yield (typically $>95: 5$ er) [40]. Very recently, Motomu Kanai et al. reported a copper-catalyzed asymmetric addition of enynes to ketones with good functional group tolerance and this reaction does not require stoichiometric amounts of bases and additives. They also found that the species resulting from the coordination of $(S, S)$-Ph-BPE ligands to mesitylcopper (CuMes) is more reactive and efficient. In their work, a $(S, S)$-Ph-BPE ligand has been introduced into the catalytic asymmetric nucleophilic addition of hydrocarbons to ketones at low temperature $\left(-30^{\circ} \mathrm{C}\right)$ with high ee values [41].

Although there are so many experiments that have been successful in the synthesis of target products, the above reactions mediated by organometallic catalysts just give moderate ee values in general, which hinders the above asymmetric reactions to construct tetrasubstituted centres in practice. Although the proposed mechanism was briefly described in the experimental paper published [41], the detailed mechanism of such a copper-catalyzed asymmetric nucleophilic addition of enynes to ketones as well as the origin of the stereochemistry, however, is much less known. Although it is well-known that the chiral environment is controlled by classical steric and electronic factors and the rigidity of the ligand framework [42-53], the effects of chiral ligands on such asymmetric reactions are still uncertain. Therefore, it is hard to precisely evaluate the key parameters of chiral ligands associated with high ee values, which has become an obstacle for designing new effective chiral ligands.

Copper-catalyzed asymmetric addition of olefin-derived nucleophiles to ketones was performed in Yang Yang, Ian B. Perry, Gang Lu, Peng Liu, and Stephen L. Buchwald [54], where the scientists present a computational study with the same chiral ligand in the addition of olefin to ketones. Our present investigation focuses on the origin of the stereochemistry of asymmetric nucleophilic addition of enynes to ketones. In an attempt to gain a better understanding of the inner reasons for the asymmetric 
nucleophilic addition reaction at a molecular level and to clarify how the chiral BPE-ligated copper catalysts enhance the reaction's enantioselectivity, we here carry out theoretical simulations on such reaction systems based on quantum chemistry, and this work is expected to be useful for the design of new ligands.

\section{Results and Discussion}

\subsection{Mechanism of the BPE-CUMes Model System}

In this section, BPE-CuMes is used as the model species to probe the reaction mechanism. As shown in Scheme 1, the calculations predict that the entire reaction could be roughly divided into the following two parts: (1) the exchange of hydrogen from the $\alpha-\mathrm{H}$ of alkyne moiety in the enyne to the Mes fragment at the copper centre with the formation of the active intermediate IM2 and (2) the catalytic cycle to generate the final product with the recovery of the intermediate IM2.

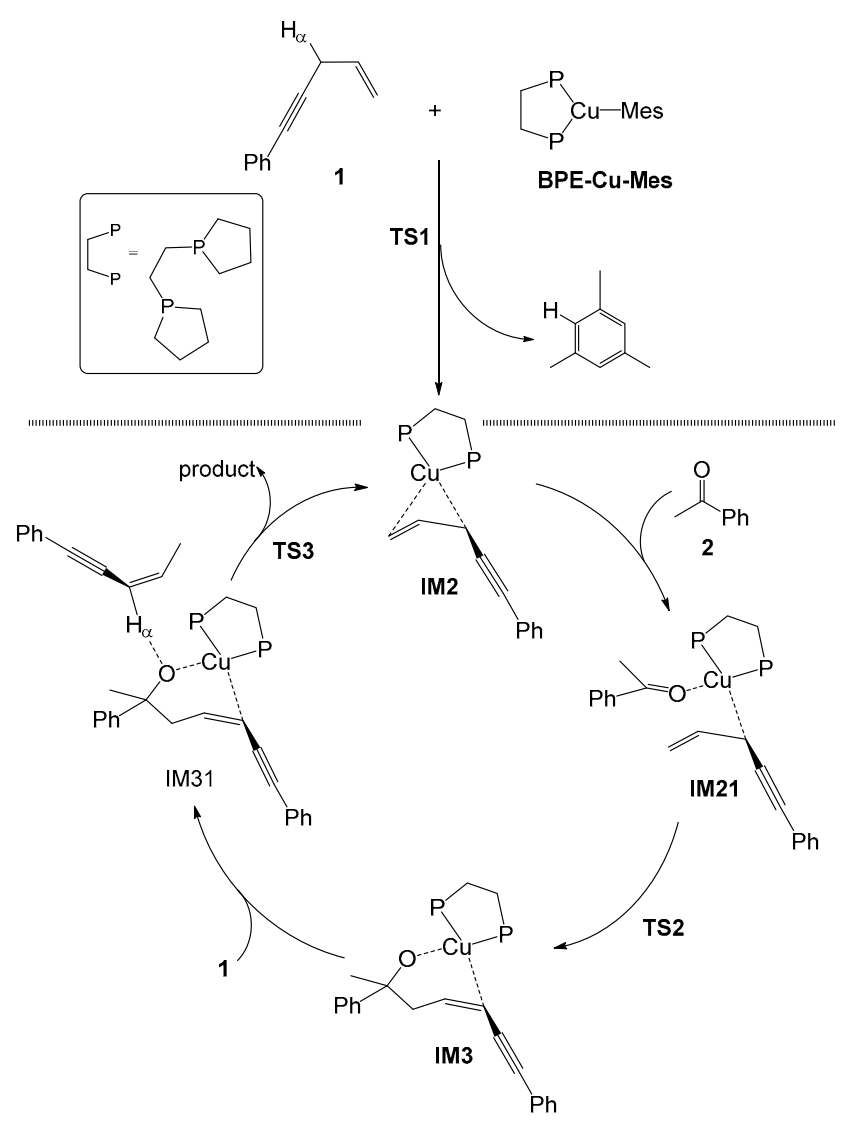

Scheme 1. Schematic diagram of the reaction process in the BPE-ligated system.

\subsubsection{Formation of the Active Intermediate IM2}

The optimized structures at the M06/6-31G(d,p) level and the relative energies diagram at the M06(SMD, THF) $/ 6-311+\mathrm{G}(\mathrm{d}, \mathrm{p})$ level in the modeled BPE-ligated system are depicted in Figures 1 and 2, respectively. 


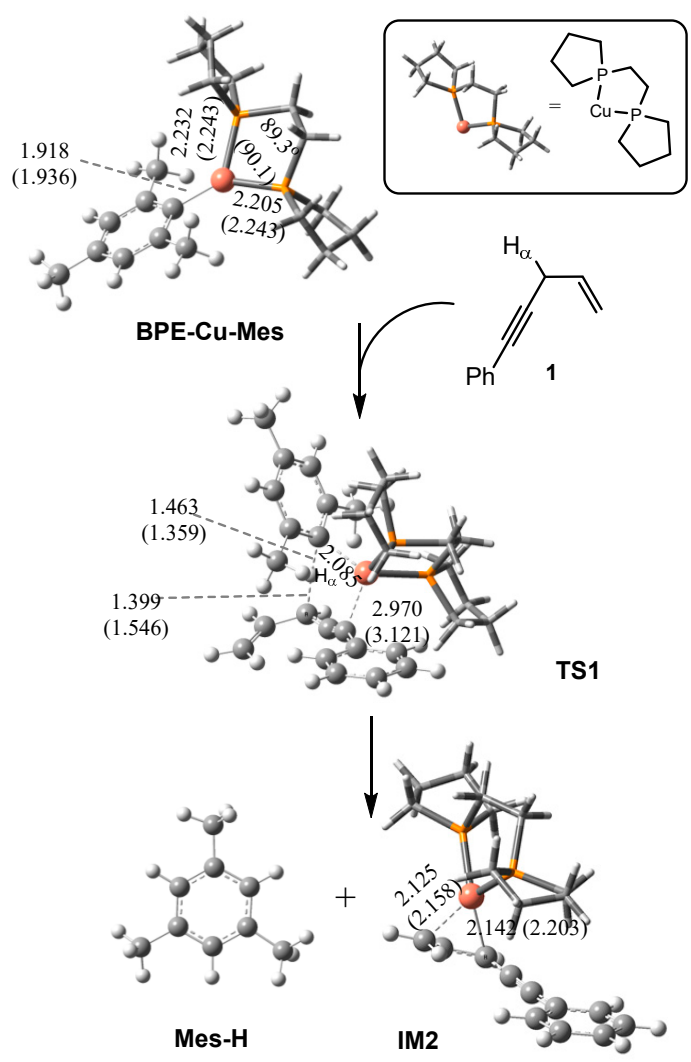

Figure 1. Optimized structures along the reaction from the reactants to IM2 at the M06/6-31G(d,p) level and B3LYP/6-31G(d,p) in parentheses. Bond lengths are in angstroms and the angles are in degrees.

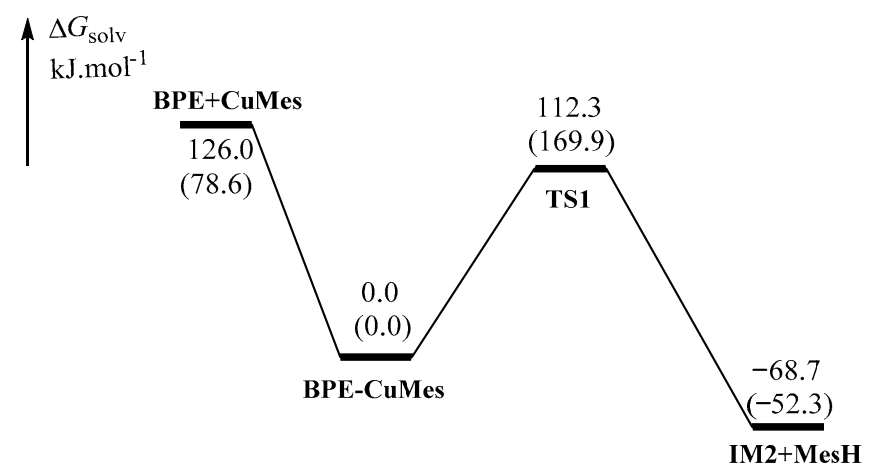

Figure 2. Energy diagram for the formation of the intermediate IM2. $\Delta G_{\text {solv }}\left(\right.$ in kJ mol ${ }^{-1}$ ) are calculated at the M06(SMD,THF)/6-311+G(d,p) level; $\Delta G_{\text {solv }}$ (in $\mathrm{kJ} \mathrm{mol}^{-1}$ ) at the $\mathrm{B} 3 \mathrm{LYP} /(\mathrm{SMD}, \mathrm{THF}) / 6-311+\mathrm{G}(\mathrm{d}, \mathrm{p})$ level are listed in parentheses.

First, the reaction is triggered by the coordination of the modelled ligand BPE to the copper end in CuMes, which generates a BPE-CuMes complex. This complex is characterised by a tridentate-coordinated copper centre with two Cu-P bonds of 2.232 and $2.205 \AA$, respectively, and the $\mathrm{P}-\mathrm{Cu}-\mathrm{P}$ bite angle is calculated to be $89.3^{\circ}$. Steered molecular dynamics (SMD) calculations give that this coordination step is benefited by $126.0 \mathrm{~kJ} \mathrm{~mol}^{-1}$ in the Gibbs free energies in THF, suggesting that this species is easy to generate.

Next, an external substrate 1-phenyl-4-penten-1-yne 1 gets close to the BPE-Cu-Mes complex accomplished by cleavage of the $\mathrm{C}-\mathrm{H}(\alpha)$ bond of the alkyne moiety via TS1. This species is characterized by an elongated $\mathrm{C}-\mathrm{H}(\alpha)$ bond of $1.399 \AA$ and a shortened $\mathrm{C}(\mathrm{Mes})-\mathrm{H}$ bond of $1.463 \AA$. This step corresponds to the migration of one $\alpha$-hydrogen from substrate 1 to the Mes moiety. As a 
result, the exchange of hydrogen from the enyne moiety to the Mes fragment takes place, which is followed by the release of one mesitylene (MesH) molecule and the formation of the intermediate IM2. SMD calculations indicate that the above step benefits from $68.7 \mathrm{~kJ} \mathrm{~mol}^{-1}$ in Gibbs free energies with a moderate energy barrier of $112.3 \mathrm{~kJ} \mathrm{~mol}^{-1}$, meaning that the formation of IM2 is favoured in thermodynamics.

For IM2, the $\mathrm{Cu}-\mathrm{C}(\alpha)$ distance of $2.142 \AA$ with the occupied orbital of $1.996 \mathrm{e}$ from natural bond orbital (NBO) analysis identifies IM2 as a metalized enyne species.

\subsubsection{Catalytic Cycle Over IM2}

The optimized structures at the M06/6-31G $(\mathrm{d}, \mathrm{p})$ level and the SMD energies diagram at the M06/6-311+G(d,p) level along the catalytic cycle in the modelled BPE-ligated system are depicted in Figures 3 and 4, respectively.

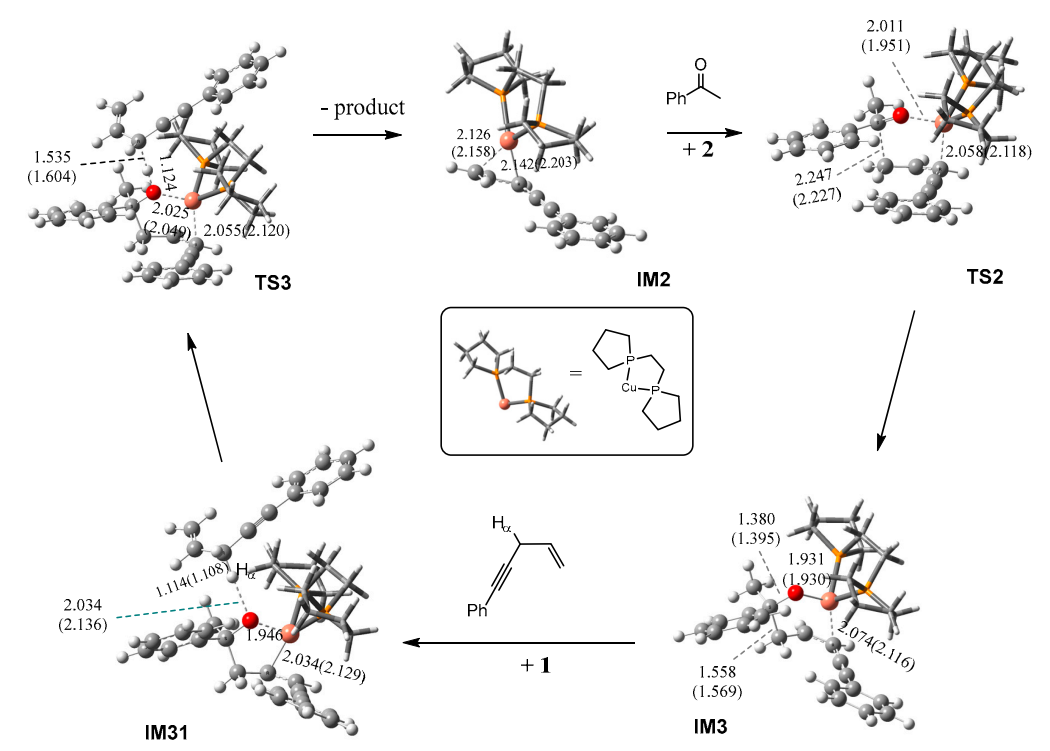

Figure 3. Optimized structures along the catalytic cycle at the M06/6-31G(d,p) level and the B3LYP/6-31G $(d, p)$ in parentheses. Bond lengths are in angstroms and the angles are in degrees.

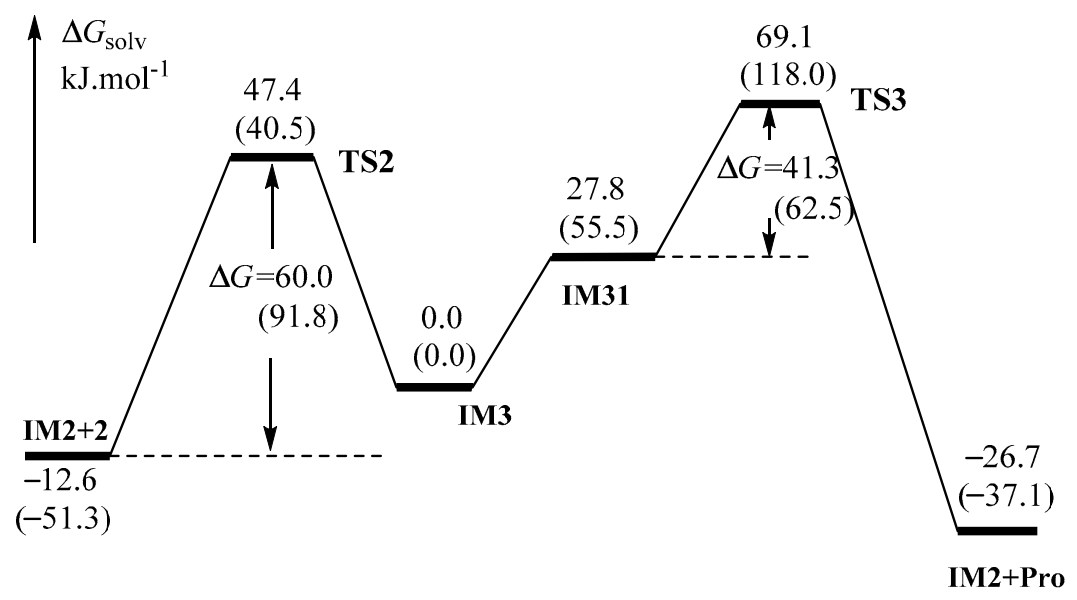

Figure 4. Evolution of energies along the reaction routes in the THF system. $\Delta G_{\text {solv }}$ (in kJ mol ${ }^{-1}$ ) for various species are calculated at the M06(SMD, THF) $/ 6-311+\mathrm{G}(\mathrm{d}, \mathrm{p})$ level; $\Delta G_{\text {solv }}\left(\right.$ in $\mathrm{kJ} \mathrm{mol}^{-1}$ ) at the B3LYP(SMD, THF)/6-311+G(d,p) level are listed in parentheses. 
As shown in Figure 3, the catalytic cycle starts from the coordination of an acetophenone 2 molecule getting close to the copper end of IM2 accomplished by the attack of the carbonyl to the ene end of the metalized enyne via TS2.

For TS2, the closest C-C distance between carbonyl and ene moieties shortens to $2.247 \AA$. This suggests that the formation of the $\mathrm{C}-\mathrm{C}$ bond occurs with the ketone addition to the double bond of 1-phenyl-4-penten-1-yne. In IM3, the C(carbonyl)-C(eneye) bond of $1.558 \AA$ indicates that acetophenone addition to the 1-phenyl-enyne was completed. SMD calculations indicate the above step benefits from $47.4 \mathrm{~kJ} \mathrm{~mol}^{-1}$ in Gibbs free energies with a smaller energy barrier of $60.0 \mathrm{~kJ} \mathrm{~mol}^{-1}$, meaning that this ketone addition process occurs easily.

From IM3, another 1 could interact with the $\mathrm{O}$ end of IM3 with the formation of the molecule-molecule complex IM31. For IM31, the linear $\mathrm{C}-\mathrm{H}(\alpha) \cdots \mathrm{O}$ pattern with the $\mathrm{C}-\mathrm{H}(\alpha)$ and the $\mathrm{O}-\mathrm{H}(\alpha)$ bond of 1.114 and $2.034 \AA$ shows that there might be a hydrogen bond to connect IM3 and the external 1.

From IM31, the reaction continues to generate the final product with the recovery of the active intermediate IM2 via TS3. In TS3, the $\mathrm{O}-\mathrm{H}(\alpha)$ bond is remarkably decreased to $1.124 \AA$, and the $\mathrm{C}-\mathrm{H}(\alpha)$ bond increases to $1.535 \AA$. This suggests that the $\mathrm{O}-\mathrm{H}(\alpha)$ bond forms with the cleavage of the $\mathrm{C}-\mathrm{H}(\alpha)$ bond of the external $\mathbf{1}$, which corresponds to the metallization of the substrate enyne in the catalytic cycle. SMD calculations indicate the above step with a smaller energy barrier of $41.3 \mathrm{~kJ} \mathrm{~mol}^{-1}$ in Gibbs free energies.

Combined with the reaction mechanism in part $\mathbf{1}$ and $\mathbf{2}$ in the model BPE-ligated system, it could be found that the formation of the active intermediate IM2 is vital for the catalytic reaction. In Section 2.1.1, IM2 is generated from the metallization of the enyne via TS1 with the energy barrier of $112.3 \mathrm{~kJ} \mathrm{~mol}^{-1}$. However, once IM2 results, the metallization of the enyne could advantageously take place via TS3, for this step bears a relatively smaller energy barrier of $41.3 \mathrm{~kJ} \mathrm{~mol}^{-1}$. Therefore, the active intermediate IM2 plays the role of the real catalyst for the reaction and BPE-Cu-Mes acts as a precursor.

As shown in Figure 4, to obtain the final products, the reaction must overcome two energy summits located at TS2 and TS3 in the catalytic cycle. SMD calculations (both M06 and B3LYP) predict the larger barrier via TS2 in the catalytic cycle, which means that the metallization of the enyne via TS2 should be the rate-determining step (RDS) for this reaction.

On the other hand, SMD calculations place TS2 on the energy top in the catalytic cycle. It should be emphasized that the distribution of products should predominantly depend on the evolution of IM3 in the energy trap. Because the reverse energy barrier from IM3 to IM2 via TS2 is much larger than IM31 to product via TS3, if IM3 forms, the reverse process to reactants is hindered and the reaction should give rise to the final products irreversibly. Therefore, it is reasonable to deduce that TS2, corresponding to the ketone addition step, is the stereo-controlling the transition state under the asymmetric factors introduced in the reaction systems.

\subsection{Stereochemistry of Such Reactions}

In order to explore the factors controlling stereoselectivity in detail, we extend our calculations on the chiral-ligated reaction system based on the $(S, S)$-Ph-BPE diphosphate ligands (see Computational Details). This ligand has been found to possess remarkable chiral recognition ability and broad applicability in various transitional metal-catalyzed asymmetric reactions, and was successfully employed in asymmetric titled reactions. In the series of reports on the asymmetric reaction of ketones, the yields of such reactions are respectable with excellent enantioselectivities as high as $97 \%$ (R-product) [41].

As mentioned above, the distribution of the racemic products is closely controlled in the ketone addition step. Therefore, to reduce computational costs, the following investigations on the stereochemistry of these ligated systems just focus on the structures of addition transition states (TS2s). The optimized TS2s are provided in Figure 5 (to give brief expression, $(S, S)$-Ph-BPE is marked 
as $\left.L_{P h}\right)$. The configuration of products and the SMD energies of these TS2s at the M06/6-311+G(d,p) level are summarized in Table 1.

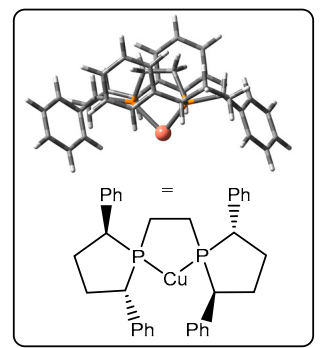

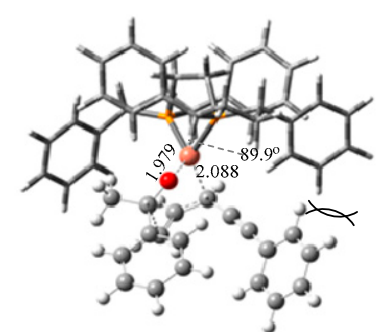

$\mathrm{L}_{\mathrm{Ph}}$-right-si-TS2

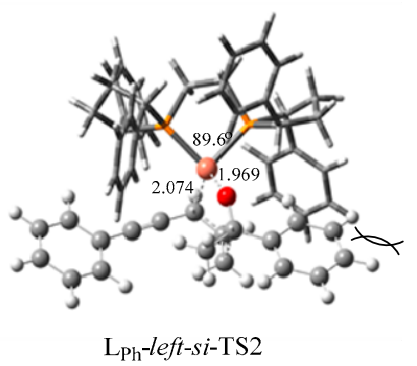

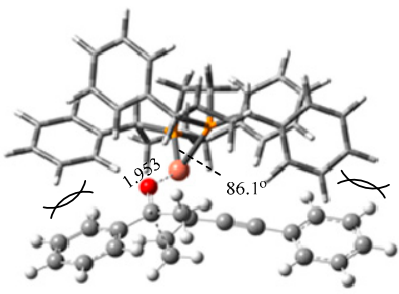

$\mathrm{L}_{\mathrm{Ph}}$-right-re-TS2

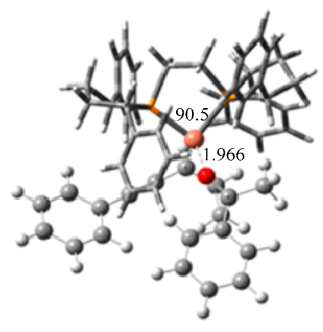

$\mathrm{L}_{\mathrm{Ph}}$-left-re-TS2

Figure 5. Three-dimensional (3D) model of stereo-controlling transition states (TS2s) at the M06/6-31G(d,p) level in the $(S, S)-P h-B P E$ ligand system.

Table 1. $\Delta G$ values of competing TS2s in the $(S, S)$-Ph-PBE system.

\begin{tabular}{cccc}
\hline TS2s & P-cu-p Angle & Configuration of Products & $\Delta \boldsymbol{G}(\mathbf{k J} / \mathbf{m o l})$ \\
\hline $\mathrm{L}_{\mathrm{Ph}}$-right-si & $89.9^{\circ}$ & $\mathrm{S}$ & 15.6 \\
$\mathrm{~L}_{\mathrm{Ph}}$-right-re & $86.1^{\circ}$ & $\mathrm{R}$ & 43.5 \\
$\mathrm{~L}_{\mathrm{Ph}}$-left-si & $89.6^{\circ}$ & $\mathrm{S}$ & 33.4 \\
$\mathrm{~L}_{\mathrm{Ph}}$-left-re & $90.5^{\circ}$ & $\mathrm{R}$ & 0.0 \\
\hline
\end{tabular}

\subsubsection{Stereoselectivity of the (S,S)-Ph-BPE System}

Similar to the model system, these four ligated $\mathrm{Cu}$ catalysts also bear a gross structure of a $\mathrm{P}-\mathrm{Cu}-\mathrm{P}$ network. These TS2s are characterized by the location of the phenyl ring of the enyne with respect to the ligand. As these ligands possess $C_{2}$-symmetry in the structure of the right-TS2s, the phenyl ring of the enyne keeps almost on the right side in Figure 5. In contrast, the phenyl ring of the enyne could alternatively adopt on the left side for the left-TS2s. Besides this, two attack modes of the enyne to the ketone are available: in re-TS2s, the enyne could attack the ketone from the re-face to raise the product in $R$-configuration; while in $s i$-TS2s, the enyne could attack the ketone from the si-face to generate the product in $S$-configuration. Therefore, in the actual system, four transition states result: $\mathrm{L}_{\mathrm{Ph}}$-right-re-TS2 and $\mathrm{L}_{\mathrm{Ph}}$-left-re-TS2 could provide the final product in $R$-configuration; the other two, $\mathrm{L}_{\mathrm{Ph}}$-right-si-TS2 and $\mathrm{L}_{\mathrm{Ph}}$-left-si-TS2, generate the final product in S-configuration.

For the $(S, S)$-Ph-BPE-ligated system, it could be distinguished that two kinds of hindrance are available: mode a) the hindrance between the phenyl ring of the ligand and the phenyl of the enyne; and mode b) the hindrance between the phenyl ring of the ligand and the phenyl of acetophonone. The $\mathrm{L}_{\mathrm{Ph}}$-right-si-TS2 suffers from the mode a hindrance; the $\mathrm{L}_{\mathrm{Ph}}$-left-si-TS2 bears the mode $\mathrm{b}$ hindrance. Also, there exists both modes of hindrance for the $\mathrm{L}_{\mathrm{Ph}}$-right-re-TS2, and there exists no remarkable hindrance for the the $\mathrm{L}_{\mathrm{Ph}}$-left-re-TS2. The calculations place $\mathrm{L}_{\mathrm{Ph}}$-left-re-TS2 $15.6 \mathrm{~kJ} \mathrm{~mol}^{-1}$ at the M06(SMD) $/ 6-311+G(d, p)$ level and $16.3 \mathrm{~kJ} \mathrm{~mol}^{-1}$ at the B3LYP(SMD)/6-311+G(d,p) level lower than the competing translon state $\mathrm{L}_{\mathrm{Ph}}$-right-si-TS2 in Gibbs free energies. Because $R$-configuration product 
is yielded from $\mathrm{L}_{\mathrm{Ph}}$-left-re-TS2, $R$-product would be the predominant product with a high ee value in the titled addition reaction, which is in good agreement with the experimental observation ( $R$-product with $97 \%$ ee) [41].

Furthermore, it is worth mentioning that for the above four transition states, the energy discrepancy is related to the $\mathrm{P}-\mathrm{Cu}-\mathrm{P}$ bite angle. The larger the $\mathrm{P}-\mathrm{Cu}-\mathrm{P}$ angle is, the lighter the tension of the $(S, S)$-Ph-BPE-Cu moiety, which is associated with the smaller hindrance suffered in $\mathrm{L}_{\mathrm{Ph}}$-TS2s, and therefore makes this transition state favoured in relative energies.

In addition, we also compared the $\Delta G$ values at different levels. As shown in Table 2, $R$-configuration product is yielded from $\mathrm{L}_{\mathrm{Ph}}$-left-re-TS2 and is the predominant product.

Table 2. $\Delta G$ values of competing TS2s in the $(S, S)$-Ph-BPE system calculated at different levels.

\begin{tabular}{ccccc}
\hline TS2s & $\boldsymbol{\Delta} \boldsymbol{G}_{\text {solv-M06 }}$ & $\boldsymbol{\Delta} \boldsymbol{G}_{\text {solv-B3 }}$ & $\boldsymbol{\Delta} \boldsymbol{G}_{\text {gas-M06 }}$ & $\boldsymbol{\Delta} \boldsymbol{G}_{\text {gas-B3 }}$ \\
\hline $\mathrm{L}_{\mathrm{Ph}}$-right-si & 15.6 & 16.3 & 6.2 & 12.0 \\
$\mathrm{~L}_{\mathrm{Ph}}$-right-re & 43.5 & 30.8 & 26.9 & 25.4 \\
$\mathrm{~L}_{\mathrm{Ph}}$-left-si & 33.4 & 23.2 & 19.4 & 21.1 \\
$\mathrm{~L}_{\mathrm{Ph}}$-left-re & 0.0 & 0.0 & 0.0 & 0.0 \\
\hline
\end{tabular}

$\Delta G_{\text {solv-M06 }}$ (in kJ mol ${ }^{-1}$ ) are calculated at the M06(SMD,THF)/6-311+G(d,p) level in THF solvent; $\Delta G_{\text {solv-B3 }}$ (in $\mathrm{kJ} \mathrm{mol}^{-1}$ ) are calculated at the B3LYP(SMD,THF)/6-311+G(d,p) level in THF solvent; $\Delta G_{\text {gas-M06 }}\left(\right.$ in $\mathrm{kJ} \mathrm{mol}^{-1}$ ) are calculated at the M06/6-31G(d,p) level in the gas phase; $\Delta G_{\text {gas-B3 }}\left(\right.$ in kJ mol $\left.^{-1}\right)$ are calculated at the B3LYP/6-31G $(\mathrm{d}, \mathrm{p})$ level in the gas phase.

\subsubsection{Origin of Stereoselectivity}

\section{a. Effect of the Structure of Chiral Ligand}

Next, the aim of the present investigation turns to the origin of the stereochemistry of the titled reaction and the influencing factor of groups at chiral sites of the BPE ligand on it. Here, we used a methyl group that was smaller in size to take the place of the phenyl rings at the $(S, S)$-BPE skeleton. The four-transition state $\mathrm{L}_{\mathrm{Me}}$-TS2s are shown in Figure 6. The configuration of products and the SMD energies of these $\mathrm{L}_{\mathrm{Me}}$-TS2s at the M06/6-311+G(d,p) level are summarized in Table 3 .

As shown in Figure 6, no remarkable hindrance between the ligand and the substrates could be found, which might be confirmed by the larger $\mathrm{P}-\mathrm{Cu}-\mathrm{P}$ angles $\left(>90^{\circ}\right)$. Correspondingly, the calculations place the energy gap between two competing transition states ca. $0.2 \mathrm{~kJ} \mathrm{~mol}^{-1}$; thus, no obvious enantioselectivity could be detected.

\section{b. Effect of the Structure of Ketone}

Furthermore, to evaluate the effect of the ketone with emphasis on its potential hindrance between the ligand, 2,4-dimethylacetophenone was used as the substrate in the $(S, S)$-Ph-PBE system. The four transition state TS2s and the relative energies are shown in Figure 7. The configuration of products and the SMD energies of these TS2s at the M06/6-311+G(d,p) level are summarized in Table 4.

Table 3. $\Delta G$ values of competing TS2s in the $(S, S)$-Me-PBE system.

\begin{tabular}{cccc}
\hline TS2s & P-Cu-P Angle & Configuration of Products & $\boldsymbol{\Delta G}_{\text {solv }}(\mathbf{k J} / \mathbf{m o l})$ \\
\hline $\mathrm{L}_{\mathrm{Me}}-$ right-si & $91.2^{\circ}$ & $\mathrm{S}$ & 0.0 \\
$\mathrm{~L}_{\mathrm{Me}}-$ right $-r e$ & $91.0^{\circ}$ & $\mathrm{R}$ & 13.3 \\
$\mathrm{~L}_{\mathrm{Me}}-$ left-si & $90.0^{\circ}$ & $\mathrm{S}$ & 17.3 \\
$\mathrm{~L}_{\mathrm{Me}}$-left-re & $90.7^{\circ}$ & $\mathrm{R}$ & 0.7 \\
\hline
\end{tabular}




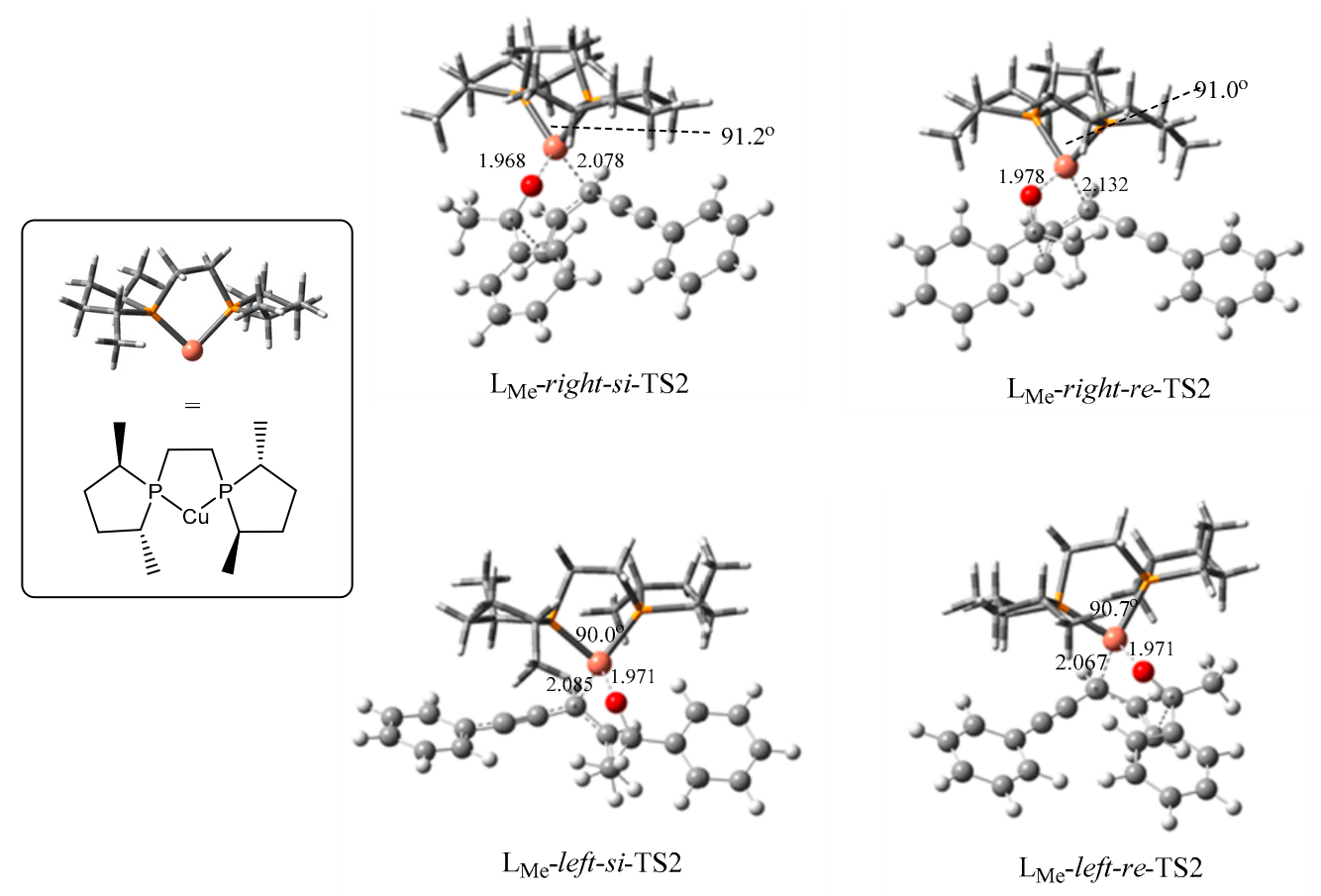

Figure 6. $3 \mathrm{D}$ model of stereo-controlling transition states (TS2s) at the M06/6-31G(d,p) in the $(S, S)-M e-B P E$ ligand system.
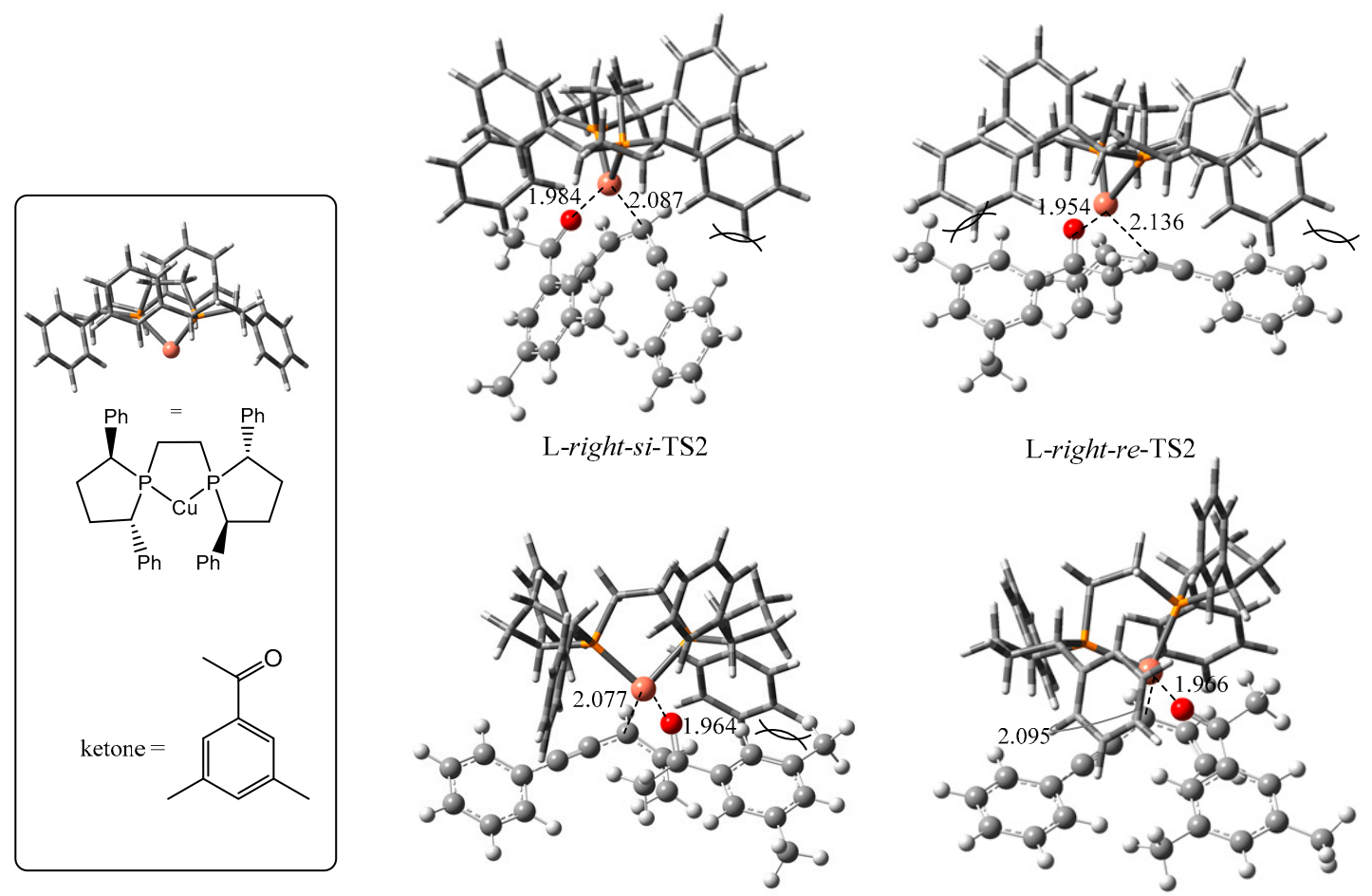

L-left-si-TS2

L-left-re-TS2

Figure 7. 3D model of stereo-controlling transition states (TS2s) at the M06/6-31G(d,p) in the 2,4-dimethylacetophenone/(S,S)-Ph-BPE ligand system. 
Table 4. $\Delta G$ values of competing TS2s in the 2,4-dimethylacetophenone/(S,S)-Ph-PBE system.

\begin{tabular}{cccc}
\hline TS2s & P-Cu-P Angle & Configuration of Products & $\boldsymbol{\Delta G}_{\text {solv }}(\mathbf{k J} / \mathbf{m o l})$ \\
\hline L-right-si & $90.0^{\circ}$ & $S$ & 13.8 \\
L-right-re & $84.9^{\circ}$ & $R$ & 39.1 \\
L-left-si & 90.1 & $S$ & 32.8 \\
L-left-re & 90.2 & $R$ & 0.0 \\
\hline
\end{tabular}

As shown in Figure 7, it could be found that those TSs possess comparable $\mathrm{P}-\mathrm{Cu}-\mathrm{P}$ angles (ca. $90^{\circ}$ ) in general as compared to that in the acetophenone $/(S, S)$-Ph-PBE system in Table 1 , which means that 2,4-dimethylacetophenone might not obviously enhance the steric hindrance between the substrates and ligands. Correspondingly, the M06(SMD) $/ 6-311+G(d, p)$ calculation places $\Delta G$ between the competing transition state L-right-si-TS2 and L-left-re-TS2 to be $13.8 \mathrm{~kJ} \mathrm{~mol}^{-1}$, and predicts that the $R$-product would be the predominant product with a good ee value. The above results imply that the ee value might not be sensitive to ketones under the $(S, S)$-Ph-PBE used, which can be supported by the corresponding experimental observation [41].

To sum up, the enantioselectivity should be controlled by the steric hindrance between substrates and ligands. When larger-size groups exist at the chiral sites of the catalyst, they could selectively make one of the competing transition states stable in terms of controlling the orientation of two substrates with respect to the $C_{2}$-symmtry ligand. In the $(S, S)$-Ph-BPE system, the $R$-configuration catalyst makes left-re-TS2 stable with the larger $\mathrm{P}-\mathrm{Cu}-\mathrm{P}$, and therefore leads to the predominant $\mathrm{R}$-product. Moreover, it is also found that the ee value significantly depends on the size of the groups at the chiral sites of the ligand: when larger groups are introduced at the chiral sites of BPE, the $\Delta G$ between the two competing transition states becomes great enough for a high ee value.

\section{Models and Computational Methods}

The previous computational literature demonstrated that the M06 [55-58] and B3LYP methods performed well for catalytic reactions based on the copper system [54,59-65]. In the present investigation, the geometrical optimizations of all the intermediates (IM) and transition states (TS) were performed using the M06 and B3LYP methods with the 6-31G(d,p) [66] basis set for all atoms. To take the entropy effects in solvents into account, single-point self-consistent reaction field (SCRF) calculations based on the SMD [67-74] model with the radii=UAHF keyword were carried out on the gas phase optimized geometries for all species. As THF was used as the solvent in the actual experiments [67], the latter calculations in the actual system were carried out with a dielectric constant $\varepsilon=7.43$ for the solvent THF. For evaluating the solvent effects, the free energies were calculated at the $\mathrm{M} 06 / 6-311+G(d, p)[60,75]$ level and added to the gas phase free energy to obtain the Gibbs energy in THF $\left(G_{\text {solv }}\right)$ at $298.15 \mathrm{~K}$. Unless otherwise stated, $G_{s o l v}$ is used in the discussion and the energy levels refer to the $G_{\text {solv }}$ scale.

All calculations were performed with the Gaussian 09 program [76]. Frequencies were calculated at the same level to confirm each stationary point to be either a minimum (no imaginary frequency) or a saddle point (unique imaginary frequency) and to obtain the zero-point correction. Details of the preliminary results are listed in the electronic supplementary materials (ESM).

The major work in the present investigation is based on the following two models (see Scheme 2). 

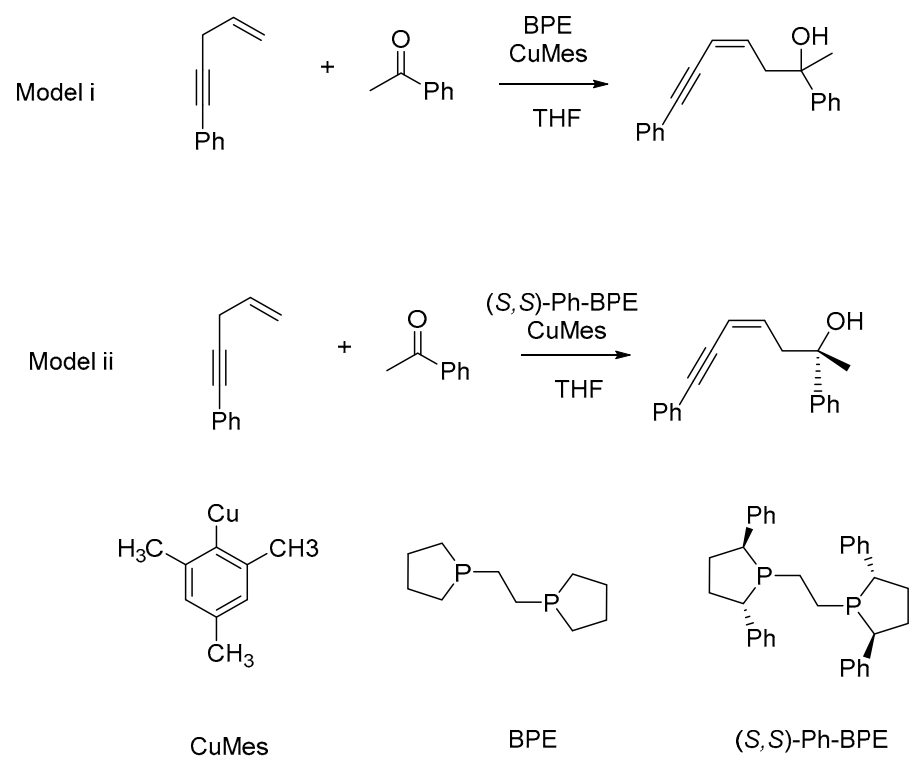

Scheme 2. Used models in the present calculation.

\section{Model i: BPE-Cu-Mes System}

The CuMes-catalyzed asymmetric reaction of carbonyl compounds suggested that the metal source with a 1:1 ratio of ligand to metal is involved. Therefore, the BPE-CuMes species in monomeric form was constructed in the present calculations.

In this section, 1-phenyl-4-penten-1-yne $\mathbf{1}$ and acetophenone $\mathbf{2}$ were employed as the substrates. The modelled non-chiral phosphine ligand BPE was introduced in the present investigation, and a monomeric ligated CuMes species was constructed as the catalytic species (Scheme 1). This treatment is designed to probe the reaction mechanism at less computational cost with acceptable calculated precision.

\section{Model ii: Chiral-(S,S)-Ph-BPE-Cu-Mes Model}

In this section, a chiral diphosphine ligand $(S, S)$-Ph-BPE-CuMes was introduced into the reaction system. This system has been used in experiments and proven to be excellent in catalytic asymmetric nucleophilic addition of conjugated acetophenone with high ee (97\%) values [41].

\section{Conclusions}

The results from the present investigations on the BPE-ligated, Cu-catalyzed enantioselective addition of enynes to ketones are summarized as follows:

For the modelled BPE-Cu-Mes system, the calculations on the BPE-CuMes system predict that the active metallized enyne intermediate acts as the catalyst for the catalytic cycle. The catalytic cycle involves two steps: (1) the ketone addition to the alkene moiety of the metallized enyne; and (2) the metallization of the enyne followed by the release of product with the recovery of the active metallized enyne intermediate. The first step accounts for the distribution of the products, and therefore is the stereo-controlling step in the chiral system.

In the chiral $(S, S)$-Ph-BPE-CuMes system, the calculations identify that the steric hindrance between the phenyl ring of the two substrates and groups at the chiral centres in the ligand skeleton is the origin of the stereoselectivity for the titled reaction. The stereoselectivity of this reaction is sensitive to the size of the groups at the chiral centres of the BPE ligand.

Supplementary Materials: The optimized structures and energies are available online at http:/ /www.mdpi.com/ 2073-4344/8/9/359/s1.

Author Contributions: H.L. performed the experiments and wrote the paper; S.Q. conceived, designed, and performed the experiments and discussed the results. M.L. and G.T. supported the analysis of data. 
Funding: This research was funded by the National Natural Science Foundation of China (grant number 21303108).

Conflicts of Interest: The authors declare no conflict of interest.

\section{References}

1. Riant, O.; Hannedouche, J. Asymmetric catalysis for the construction of quaternary carbon centres: Nucleophilic addition on ketones and ketimines. Org. Biomol. Chem. 2007, 5, 873-888. [CrossRef] [PubMed]

2. Corey, E.J.; Guzman-Perez, A. The Catalytic Enantioselective Construction of Molecules with Quaternary Carbon Stereocenters. Angew. Chem. Int. Ed. 1998, 37, 388-401. [CrossRef]

3. Fuji, K. Asymmetric Creation of Quaternary Carbon Centers. Chem. Rev. 1993, 93, 2037-2066. [CrossRef]

4. Douglas, C.J.; Overman, L.E. Catalytic asymmetric synthesis of all-carbon quaternary stereocenters. Proc. Natl. Acad. Sci. USA 2004, 101, 5363-5367. [CrossRef] [PubMed]

5. Abozeid, M.A.; Sairenji, S.; Takizawa, S.; Fujita, M.; Sasai, H. Enantioselective synthesis of tetrahydrocyclopenta [b]-indole bearing a chiral quaternary carbon center via Pd(II)-SPRIX-catalyzed C-H activation. Chem. Commun. 2017, 53, 6887-6890. [CrossRef] [PubMed]

6. Ghorai, M.K.; Halder, S.; Das, S. ; Domino Michael-Michael and Aldol-Aldol Reactions: Diastereoselective Synthesis of Functionalized Cyclohexanone Derivatives Containing Quaternary Carbon Center. J. Org. Chem. 2015, 80, 9700-9712. [CrossRef] [PubMed]

7. Yi, Y.; Lee, H.; Ho Jun, C. Rh(III)-catalyzed C-H activation reactions forming $1 \mathrm{H}$-isoindoles containing a quaternary carbon center from aryl ketones or benzylamines. Chem. Commun. 2016, 52, 10171-10174. [CrossRef] [PubMed]

8. Franckevičius, V. Palladium-catalyzed construction of quaternary carbon centers with propargylic electrophiles. Tetrahedron Lett. 2016, 57, 3586-3595. [CrossRef]

9. Dosa, P.I.; Fu, G.C. Catalytic Asymmetric Addition of $\mathrm{ZnPh}_{2}$ to Ketones: Enantioselective Formation of Quaternary Stereocenters. J. Am. Chem. Soc. 1998, 120, 445-446. [CrossRef]

10. Pályi, G.; Váradi, G.; Vizi-Orosz, A.; Markó, L. Reactivity of $\mu_{2}$-acetylenes coordinated to cobalt. Stereochemistry of the formation of butene-2-olide-4 complexes. J. Organomet. Chem. 1975, 90, 85-91. [CrossRef]

11. Váradi, G.; Horváth, I.T.; Palágyi, J.; Bak, T.; Pályi, G. On the reactivity of acetylenes coordinated to cobalt IV. The influence of tertiary phosphorous compounds on the catalytic synthesis of bifurandiones. J. Mol. Catal. 1980, 9, 457-460. [CrossRef]

12. Pályi, G.; Váradi, G.; Horváth, I.T. Activation of carbon monoxide and acetylenes by cobalt carbonyls. J. Mol. Catal. 1981, 13, 61-70. [CrossRef]

13. Bán, I.M.; Révész, M.; Bálint, I.; Váradi, G.; Palyi, G. A CNDO/2 study of ( $\mu_{2}$-actelyene) hexacarbonyl-dicobalt (CoCo) complexes. J. Mol. Struct. THEOCHEM 1982, 88, 357-370. [CrossRef]

14. Happ, B.; Bartik, T.; Zucchi, C.; Rossi, M.C.; Ghelfi, F.; Palyi, G.; Varadi, G.; Szalontai, G.; Horvath, I.T.; Guastini, C. On the reactivity of acetylenes coordinated to cobalt. 9. Effects of substitution and coordination on the 13C-NMR chemical shifts of the sp Carbons of $\left(\mu_{2}-\mathrm{R}^{1} \mathrm{C}_{2} \mathrm{R}^{2}\right) \mathrm{Co}_{2}(\mathrm{CO})_{6}$ Complexes. Molecular Structure of $\left(\mu_{2}-\mathrm{PhC}_{2} \mathrm{SiPh}_{3}\right) \mathrm{Co}_{2}(\mathrm{CO})_{6}$. Organometallics 1995, 14, 809-819. [CrossRef]

15. Kong, J.R.; Ngai, M.Y.; Krische, M.J. Highly Enantioselective Direct Reductive Coupling of Conjugated Alkynes and $\alpha$-Ketoesters via Rhodium-Catalyzed Asymmetric Hydrogenation. J. Am. Chem. Soc. 2006, 128, 718-719. [CrossRef] [PubMed]

16. Komanduri, V.; Krische, M.J. Enantioselective Reductive Coupling of 1,3-Enynes to Heterocyclic Aromatic Aldehydes and Ketones via Rhodium-Catalyzed Asymmetric Hydrogenation: Mechanistic Insight into the Role of Brønsted Acid Additives. J. Am. Chem. Soc. 2006, 128, 16448-16449. [CrossRef] [PubMed]

17. Cozzi, P.G. Enantioselective Alkynylation of Ketones Catalyzed by Zn(Salen) Complexes. Angew. Chem. Int. Ed. 2003, 42, 2895-2898. [CrossRef] [PubMed]

18. Jiang, B.; Chen, Z.; Tang, X. Highly Enantioselective Alkynylation of $\alpha$-Keto Ester: An Efficient Method for Constructing a Chiral Tertiary Carbon Center. Org. Lett. 2002, 4, 3451-3453. [CrossRef] [PubMed]

19. $\mathrm{Pu}, \mathrm{L}$. Asymmetric alkynylzinc additions to aldehydes and ketones. Tetrahedron 2003, 59, 9873-9886. [CrossRef]

20. Cozzi, P.G.; Hilgraf, R.; Zimmermann, N. Acetylenes in Catalysis: Enantioselective Additions to Carbonyl Groups and Imines and Applications Beyond. Eur. J. Org. Chem. 2004, 4095-4105. [CrossRef] 
21. Lu, G.; Li, Y.M.; Li, X.S.; Chan, A.S.C. Synthesis and application of new chiral catalysts for asymmetric alkynylation reactions. Chem. Rev. 2005, 249, 1736-1744. [CrossRef]

22. Langner, M.; Bolm, C. $C_{1}$-Symmetric Sulfoximines as Ligands in Copper-Catalyzed Asymmetric Mukaiyama-Type Aldol Reactions. Angew. Chem. Int. Ed. 2004, 43, 5984-5987. [CrossRef] [PubMed]

23. Langner, M.; Rémy, P.; Bolm, C. Highly Modular Synthesis of $C_{1}$-Symmetric Aminosulfoximines and Their Use as Ligands in Copper-Catalyzed Asymmetric Mukaiyama-Aldol Reactions. Chem. Eur. J. 2005, 11, 6254-6255. [CrossRef] [PubMed]

24. Oisaki, K.; Suto, Y.; Kanai, M.; Shibasaki, M. A New Method for the Catalytic Aldol Reaction to Ketones. J. Am. Chem. Soc. 2003, 125, 5644-5645. [CrossRef] [PubMed]

25. Müller, D.S.; Marek, I. Copper mediated carbometalation reactions. Chem. Soc. Rev. 2016, 45, 4552-4556. [CrossRef] [PubMed]

26. Zhu, X.; Chiba, S. Copper-catalyzed oxidative carbon-heteroatom bond formation: A recent update. Chem. Soc. Rev. 2016, 45, 4504-4523. [CrossRef] [PubMed]

27. Shibasaki, M.; Kanai, M. Asymmetric Synthesis of Tertiary Alcohols and $\alpha$-Tertiary Amines via Cu-Catalyzed C-C Bond Formation to Ketones and Ketimines. Chem. Rev. 2008, 108, 2853-2873. [CrossRef] [PubMed]

28. Thapa, S.; Shrestha, B.; Gurung, S.K.; Giri, R. Copper-catalysed cross-coupling: An untapped potential. Org. Biomol. Chem. 2015, 13, 4816-4827. [CrossRef] [PubMed]

29. Maaliki, C.; Thiery, E.J. Thibonnet, Emergence of Copper-Mediated Formation of C-C Bonds. Eur. J. Org. Chem. 2017, 209-228. [CrossRef]

30. Yoshikai, N.; Nakamura, E. Mechanisms of Nucleophilic Organocopper(I) Reactions. Chem. Rev. 2012, 112, 2339-2372. [CrossRef] [PubMed]

31. Jumde, R.P.; Lanza, F.; Veenstra, M.J.; Harutyunyan, S.R. Catalytic asymmetric addition of Grignard reagents to alkenyl-substituted aromatic $N$-heterocycles. Science 2016, 352, 433-437. [CrossRef] [PubMed]

32. Yang, Y.; Perry, I.B.; Buchwald, S.L. Copper-Catalyzed Enantioselective Addition of Styrene-Derived Nucleophiles to Imines Enabled by Ligand-Controlled Chemoselective Hydrocupration. J. Am. Chem. Soc. 2016, 138, 9787-9790. [CrossRef] [PubMed]

33. Kubota, K.; Watanabe, Y.; Hayama, K.; Ito, H. Enantioselective Synthesis of Chiral Piperidines via the Stepwise Dearomatization/Borylation of Pyridines. J. Am. Chem. Soc. 2016, 138, 4338-4341. [CrossRef] [PubMed]

34. Hojoh, K.; Ohmiya, H.; Sawamura, M. Synthesis of $\alpha$-Quaternary Formimides and Aldehydes through Umpolung Asymmetric Copper Catalysis with Isocyanides. J. Am. Chem. Soc. 2017, 139, $2184-2187$. [CrossRef] [PubMed]

35. Wada, R.; Shibuguchi, T.; Makino, S.; Oisaki, K.; Kanai, M.; Shibasaki, M. Catalytic Enantioselective Allylation of Ketoimines. J. Am. Chem. Soc. 2006, 128, 7687-7691. [CrossRef] [PubMed]

36. Oisaki, K.; Zhao, D.; Kanai, M.; Shibasaki, M. Catalytic Enantioselective Alkylative Aldol Reaction: Efficient Multicomponent Assembly of Dialkylzincs, Allenic Esters, and Ketones toward Highly Functionalized $\delta$-Lactones with Tetrasubstituted Chiral Centers. J. Am. Chem. Soc. 2007, 129, 7439-7443. [CrossRef] [PubMed]

37. Pulis, A.P.; Yeung, K.; Procter, D.J. Enantioselective copper catalysed, direct functionalisation of allenes via allyl copper intermediates. Chem. Sci. 2017, 8, 5240-5247. [CrossRef] [PubMed]

38. Meng, F.; Jang, H.; Jung, B.; Hoveyda, A.H. Cu-catalyzed Chemoselective Preparation of 2-(Pinacolato)boron Substituted Allylcopper Complexes and their In Stitu Site-, Diastereo-, and Enantioselective Additions to Aldehydes and Ketones. Angew. Chem. Int. Ed. 2013, 52, 5046-5051. [CrossRef] [PubMed]

39. Kawai, J.; Chikkade, P.K.; Shimizu, Y.; Kanai, M. In situ Catalytic Generation of Allylcopper Species for Asymmetric Allylation: Toward 1H-Isochromene Skeletons. Angew. Chem. Int. Ed. 2013, 52, 7177-7180. [CrossRef] [PubMed]

40. Jang, H.; Jung, B.; Hoveyda, A.H. Catalytic Enantioselective Protoboration of Disubstituted Allenes. Access to Alkenylboron Compounds in High Enantiomeric Purity. Org. Lett. 2014, 16, 4658-4661. [CrossRef] [PubMed]

41. Wei, X.F.; Xie, X.W.; Shimizu, Y.; Kanai, M. Copper(I)-Catalyzed Enantioselective Addition of Enynes to Ketones. J. Am. Chem. Soc. 2017, 139, 4647-4650. [CrossRef] [PubMed]

42. Shimizu, H.; Nagasaki, I.; Saito, K. Recent advances in biaryl-type bisphosphine ligands. Tetrahedron 2005, 61, 5405-5432. [CrossRef] 
43. Lipshutz, B.H.; Keith, J.; Papa, P.; Vivian, R. A convenient, efficient method for conjugate reductions using catalytic quantities of $\mathrm{Cu}(\mathrm{I})$. Tetrahedron Lett. 1998, 39, 4627-4630. [CrossRef]

44. Lipshutz, B.H.; Frieman, B.A.; Tomaso, A.E., Jr. Copper-in-Charcoal (Cu/C): Heterogeneous, Copper-Catalyzed Asymmetric Hydrosilylations. Angew. Chem. 2006, 118, 1281-1286. [CrossRef]

45. Lipshutz, B.H.; Frieman, B.A. CuH in a Bottle: A Convenient Reagent for Asymmetric Hydrosilylation, Angew. Chem. Int. Ed. 2005, 44, 6345-6348. [CrossRef] [PubMed]

46. Lipshutz, B.H.; Papa, P. Copper-Catalyzed Reductive Alkylations of Enones: A Novel Transmetalation Protocol. Angew. Chem. 2002, 114, 4762-4764. [CrossRef]

47. Lipshutz, B.H.; Servesko, J.M. CuH-Catalyzed Asymmetric Conjugate Reductions of Acyclic Enones. Angew. Chem. Int. Ed. 2003, 42, 4789-4792. [CrossRef] [PubMed]

48. Lipshutz, B.H.; Servesko, J.M.; Petersen, T.B.; Papa, P.P.; Lover, A.A. Asymmetric 1,4-Reductions of Hindered â-Substituted Cycloalkenones Using Catalytic SEGPHOS-Ligated CuH. Org. Lett. 2004, 6, 1273-1275. [CrossRef] [PubMed]

49. Lipshutz, B.H.; Tanaka, N.; Ta, B.R.; Lee, C.T. Chiral Silanes via Asymmetric Hydrosilylation with Catalytic CuH. Org. Lett. 2006, 8, 1963-1966. [CrossRef] [PubMed]

50. Baker, B.A.; Bošković, Ž.V.; Lipshutz, B.H. (BDP) CuH: A “Hot” Stryker's Reagent for Use in Achiral Conjugate Reductions. Org. Lett. 2008, 10, 289-292. [CrossRef] [PubMed]

51. Gallagher, B.D.; Taft, B.R.; Lipshutz, B.H. Asymmetric Conjugate Reductions of Coumarins. A New Route to Tolterodine and Related Coumarin Derivatives. Org. Lett. 2009, 11, 5374-5377. [CrossRef] [PubMed]

52. Lipshutz, B.H.; Servesko, J.M.; Taft, B.R. Asymmetric 1,4-Hydrosilylations of $\alpha, \beta$-Unsaturated Esters. J. Am. Chem. Soc. 2004, 126, 8352-8353. [CrossRef] [PubMed]

53. Moser, R.; Bošković, Ž.V.; Crowe, C.S.; Lipshutz, B.H. CuH-Catalyzed Enantioselective 1,2-Reductions of $\alpha, \beta$-Unsaturated Ketones. J. Am. Chem. Soc. 2010, 132, 7852-7853. [CrossRef] [PubMed]

54. Yang, Y.; Perry, I.B.; Lu, G.; Liu, P.; Buchwald, S.L. Copper-catalyzed asymmetric addition of olefin-derived nucleophiles to ketones. Science 2016, 353, 144-150. [CrossRef] [PubMed]

55. Lipshutz, B.H.; Chrisman, W.; Noson, K.; Papa, P.; Sclafani, J.A.; Vivian, R.W.; Keith, J.M. Copper Hydride-Catalyzed Tandem 1,4-Reduction/Alkylation Reactions. Tetrahedron 2000, 56, 2779-2788. [CrossRef]

56. Zhao, Y.; Truhlar, D. The M06 suite of density functionals for main group thermochemistry, thermochemical kinetics, noncovalent interactions, excited states, and transition elements: Two new functionals and systematic testing of four M06-class functionals and 12 other functional. Theor. Chem. Acc. 2008, 120, 215-241.

57. Zhao, Y.; Truhlar, D. Density Functionals with Broad Applicability in Chemistry. Acc. Chem. Res. 2008, 41, 157-167. [CrossRef] [PubMed]

58. Bryantsev, V.S.; Diallo, M.S.; Duin, A.C.T.; Goddard, W.A., III. Evaluation of B3LYP, X3LYP, and M06-Class Density Functionals for Predicting the Binding Energies of Neutral, Protonated, and Deprotonated Water Clusters. J. Chem. Theory Comput. 2009, 5, 1016-1026. [CrossRef] [PubMed]

59. Jacquemin, D.; Perpète, E.A.; Ciofini, I.; Adamo, C.; Valero, R.; Zhao, Y.; Truhlar, D.G. On the Performances of the M06 Family of Density Functionals for Electronic Excitation Energies. J. Chem. Theory Comput. 2010, 6, 2071-2085. [CrossRef] [PubMed]

60. Shi, S.L.; Xu, L.W.; Oisaki, K.; Kanai, M.; Shibasaki, M. Identification of Modular Chiral Bisphosphines Effective for $\mathrm{Cu}(\mathrm{I})$-Catalyzed Asymmetric Allylation and Propargylation of Ketones. J. Am. Chem. Soc. 2010, 132, 6638-6639. [CrossRef] [PubMed]

61. Liu, H.Y.; Zhang, W.; He, L.; Luo, M.L.; Qin, S. Computational investigations on the phosphine-ligated $\mathrm{CuH}$-catalyzed conjugate reduction of $\alpha-\beta$ unsaturated ketones: Regioselectivity and stereoselectivity. RSC Adv. 2014, 4, 5726-5733. [CrossRef]

62. Zhang, W.; Li, W.Y.; Qin, S. Origins of enantioselectivity in the chiral diphosphine-ligated CuH-catalyzed asymmetric hydrosilylation of ketones. Org. Biomol. Chem. 2012, 10, 597-604. [CrossRef] [PubMed]

63. Hong, S.; Huber, S.M.; Gagliardi, L.; Cramer, C.C.; Tolman, W.B. Copper(I)-r-Ketocarboxylate Complexes: Characterization and $\mathrm{O} 2$ Reactions That Yield Copper-Oxygen Intermediates Capable of Hydroxylating Arenes. J. Am. Chem. Soc. 2007, 129, 14190-14192. [CrossRef] [PubMed] 
64. Bar-Nahum, I.; Gupta, A.K.; Huber, S.M.; Ertem, M.Z.; Cramer, C.J.; Tolman, W.B. Reduction of Nitrous Oxide to Dinitrogen by a Mixed Valent Tricopper-Disulfido Cluster. J. Am. Chem. Soc. 2009, 131, 2812-2814. [CrossRef] [PubMed]

65. Cramer, C.J.; Gour, J.R.; Kinal, A.; Wloch, M.; Piecuch, P.; Moughal Shahi, A.R.; Gagliardi, L. Stereoelectronic Effects on Molecular Geometries and State-Energy Splittings of Ligated Monocopper Dioxygen Complexes. J. Phys. Chem. A. 2008, 112, 3754-3767. [CrossRef] [PubMed]

66. Tabuchi, K.; Ertem, M.Z.; Sugimoto, H.; Kunishita, A.; Tano, T.; Fujieda, N.; Cramer, C.J.; Itoh, S. Reactions of Copper(II)-Phenol Systems with $\mathrm{O}_{2}$ : Models for TPQ Biosynthesis in Copper Amine Oxidases. Inorg. Chem. 2011, 50, 1633-1647. [CrossRef] [PubMed]

67. Kumsapaya, C.; Bobuatong, K.; Khongpracha, P.; Tantirungrotechai, Y.; Limtrakul, J. Mechanistic Investigation on 1,5- to 2,6-Dimethylnaphthalene Isomerization Catalyzed by Acidic $\beta$ Zeolite: ONIOM Study with an M06-L Functional. J. Phys. Chem. C 2009, 113, 16128-16137. [CrossRef]

68. Marenich, A.V.; Cramer, C.J.; Truhlar, D.G. Universal Solvation Model Based on Solute Electron Density and on a Continuum Model of the Solvent Defined by the Bulk Dielectric Constant and Atomic Surface Tensions. J. Phys. Chem. B 2009, 113, 6378-6396. [CrossRef] [PubMed]

69. Saielli, G. Differential Solvation Free Energies of Oxonium and Ammonium Ions: Insights from Quantum Chemical Calculations. J. Phys. Chem. A 2010, 114, 7261-7265. [CrossRef] [PubMed]

70. Gusev, D.G. Assessing the Accuracy of M06-L Organometallic Thermochemistry. Organometallics 2013, 32, 4239-4243. [CrossRef]

71. Chen, X.B.; Liu, Z.C.; Lin, X.R.; Huang, R.; Yan, S.J.; Lin, J. Highly Diastereoselective Convergent Synthesis of Polycyclic Pyrroles with Consecutive Quaternary Stereocenters: Cascade Construction of Multiple C-C and C-Hetero Bonds. ACS Sustain. Chem. Eng. 2014, 2, 2391-2398. [CrossRef]

72. Ribeiro, R.F.; Marenich, A.V.; Cramer, C.J.; Truhlar, D.G. Prediction of SAMPL 2 aqueous solvation free energies and tautomeric ratios using the SM8, SM8AD, and SMD solvation models. J. Comput. Aided Mater. 2010, 24, 317-333. [CrossRef] [PubMed]

73. Marenich, A.V.; Cramer, C.J.; Truhlar, D.G. Performance of SM6, SM8, and SMD on the SAMPL1 Test Set for the Prediction of Small-Molecule Solvation Free Energies. J. Phys. Chem. B 2009, 113, 4538-4543. [CrossRef] [PubMed]

74. Halim, M.A.; Shaw, D.M.; Poirier, R.A. Medium effect on the equilibrium geometries, vibrational frequencies and solvation energies of sulphanilamide. J. Mol. Struct. THEOCHEM. 2010, 960, 63-72. [CrossRef]

75. Tran, A.T.; Liu, P.; Houk, K.N.; Nicholas, K.M. Regioselectivity in the Cu(I)-Catalyzed [4+2]-Cycloaddition of 2-Nitrosopyridine with Unsymmetrical Dienes. J. Org. Chem. 2014, 79, 5617-5626. [CrossRef] [PubMed]

76. Frisch, M.J.; Trucks, G.W.; Schlegel, H.B.; Scuseria, G.E.; Robb, M.A.; Cheeseman, J.R.; Scalmani, G.; Barone, V.; Petersson, G.A.; Nakatsuji, H.; et al. Gaussian 09; Revision A.02; Gaussian, Inc.: Wallingford, CT, USA, 2009. 